\title{
The health services burden of heart failure: an analysis using linked population health data-sets
}

\author{
Jane Robertson ${ }^{1,5^{*}}$, Patrick McElduff ${ }^{2}$, Sallie-Anne Pearson ${ }^{3}$, David A Henry ${ }^{1,4}$, Kerry J Inder ${ }^{1}$ and John R Attia ${ }^{1,2}$
}

\begin{abstract}
Background: The burden of patients with heart failure on health care systems is widely recognised, although there have been few attempts to quantify individual patterns of care and differences in health service utilisation related to age, socio-economic factors and the presence of co-morbidities. The aim of this study was to assess the typical profile, trajectory and resource use of a cohort of Australian patients with heart failure using linked populationbased, patient-level data.

Methods: Using hospital separations (Admitted Patient Data Collection) with death registrations (Registry of Births, Deaths and Marriages) for the period 2000-2007 we estimated age- and gender-specific rates of index admissions and readmissions, risk factors for hospital readmission, mean length of stay (LOS), median survival and bed-days occupied by patients with heart failure in New South Wales, Australia.

Results: We identified 29,161 index admissions for heart failure. Admission rates increased with age, and were higher for males than females for all age groups. Age-standardised rates decreased over time (256.7 to $237.7 /$ 100,000 for males and 235.3 to $217.1 / 100,000$ for females from 2002-3 to 2006-7; $p=0.0073$ adjusted for gender). Readmission rates (any cause) were $27 \%$ and $73 \%$ at 28-days and one year respectively; readmission rates for heart failure were $11 \%$ and $32 \%$ respectively. All cause mortality was $10 \%$ and $28 \%$ at 28 days and one year. Increasing age was associated with more heart failure readmissions, longer LOS and shorter median survival. Increasing age, increasing Charlson comorbidity score and male gender were risk factors for hospital readmission. Cohort members occupied 954,888 hospital bed-days during the study period (any cause); 383,646 bed-days were attributed to heart failure admissions.

Conclusions: The rates of index admissions for heart failure decreased significantly in both males and females over the study period. However, the impact on acute care hospital beds was substantial, with heart failure patients occupying almost 200,000 bed-days per year in NSW over the five year study period. The strong age-related trends highlight the importance of stabilising elderly patients before discharge and community-based outreach programs to better manage heart failure and reduce readmissions.
\end{abstract}

Keywords: Heart failure, Hospitalization, Health services research, Australia

\footnotetext{
* Correspondence: jane.robertson@newcastle.edu.au

${ }^{1}$ School of Medicine and Public Health, The University of Newcastle,

Newcastle, Australia

${ }^{5}$ Clinical Pharmacology, Calvary Mater Hospital, The University of Newcastle,

Clinical Sciences Building, Waratah, NSW 2298, Australia

Full list of author information is available at the end of the article
} 


\section{Background}

Heart failure is associated with considerable morbidity and poor survival. It is characterised by numerous hospital readmissions and extensive use of health care resources [1-3]. The resulting substantial burden on health care systems and the associated costs are a consequence of ageing populations and improvements in the medical management of heart failure with the use of therapies such as beta-blockers, ACE inhibitors, aldosterone inhibitors and device therapies that prolong survival after ischaemic heart damage or heart failure related to hypertension and valvular heart disease.

There has been limited documentation of the health system impacts of heart failure in the Australian community. Morbidity estimates have typically been derived by applying international chronic heart failure incidence and prevalence data to Australian population estimates [4]. More direct estimates have been derived from the National Hospital Morbidity Data (NHMD) collection [5]. This information, however, is based on aggregated data collections, with no analysis at individual patient level.

Patient-level data are required to examine individual patterns of care, and differences in outcomes related to age, socio-demographic factors, and the presence of comorbidities. In Australia, there is universal, publicly funded coverage for hospital and community-based medical services. Consequently, there are a number of administrative data sets that provide comprehensive coverage of patients with heart failure at the national or state level. Most experience with the analysis of linked health data-sets has been in Western Australia, which has validated the use of administrative data to identify patients with heart failure [6]. Although the rate of index hospital admission has fallen, the burden of disease has increased because of improved survival and the ageing of the community [7].

A capacity for linkage of publicly funded health administrative data sets at the level of the individual patient has recently become available in Australia's most populous state, New South Wales (NSW). To inform planning for care of individuals in NSW suffering from heart failure we performed an analysis of the NSW linked data-sets. We measured the rates of index (first) admissions for heart failure, the readmission rates, mortality and median survival from first admission. To assess the burden of disease on the healthcare system, we examined the average length of stay (LOS) for the index admission, readmissions in the first year, and the impact of co-morbidities on readmission rates. Finally, we calculated the bed-days occupied by patients with heart failure during the study period.

\section{Methods}

Access to the relevant NSW data-sets was through the Centre for Health Record Linkage (CHeReL; http://www. cherel.org.au).

\section{Data sets}

Records were drawn from the NSW Admitted Patient Data Collection (APDC; representing all separations in public and private hospitals in NSW, including discharges, transfers and deaths) between 1 July 2000 and 30 June 2007; and death registrations (fact of death) in the NSW Registry of Births, Deaths and Marriages (RBDM) for the years 2000-2007.

\section{Definitions}

\section{Heart failure cohort}

The cohort comprised all NSW residents aged $\geq 45$ years with a first (index) admission for heart failure i.e. a principal hospital discharge (separation) code for heart failure (ICD-10 code I50) or hypertensive heart disease (I11, I13) in the APDC between 1 July 2002 and 30 June 2007. Hypertensive heart disease was included in the definition based on evidence that some cases of heart failure are classified under this rubric [8].

\section{Index admission for heart failure}

An index admission was defined by the absence of a heart failure separation code (any diagnostic position) in the two years prior to the eligible admission.

\section{Readmissions}

Readmissions were counts of patients re-presenting at NSW hospitals for any cause within one month (28 days) and one year after the index admission for heart failure. Heart failure readmissions were any readmission where the principal separation code was heart failure (I50) or hypertensive heart disease (I11, I13).

\section{Co-morbidities}

We used the validated Charlson Index as a co-morbidity measure using an algorithm based on the work of Sandarajaran [9]. Given that heart failure is included in the Charlson Index and all patients had heart failure, no point was given for this. Co-morbidities were assessed in two ways: firstly, by examining hospital separation codes (all positions) at the index admission; and secondly by including separation codes from the index admission and all admissions in the two years prior to the index admission combined.

\section{Burden of disease}

We calculated actual bed-days occupied due to index admissions and readmissions.

\section{Geography}

Geography was defined using the Accessibility/Remoteness Index of Australia (ARIA) [10]. 


\section{Socio-economic status}

Socio-economic status was defined using the SEIFA (SocioEconomic Indexes for Areas) Index [11] based on 2006 Australian Census responses, and divided into quintiles.

\section{Data linkage}

We used extracts of linked hospital separation data from the APDC with RBDM death registrations with encryption to protect the identity of individual patients. Data linkage by the CHeReL uses probabilistic matching of patients' names and other identifiers with ChoiceMaker software [12], supplemented with clerical review of doubtful matches.

\section{Statistical methods}

Age-specific rates of index (first) admissions for heart failure or hypertensive heart disease to public and private hospitals in NSW (1 July 2002-30 June 2007) were calculated by dividing the number of index events in 5-year age groups by the NSW population in that age group in that year. Age-standardised rates and 95\% confidence intervals were calculated for each year using the indirect method with the 2006 NSW census population as the reference. Trends over time were examined with linear regression models.

The proportions of patients with a readmission (any cause or heart failure) in the first month (28 days) and first year post-index admission were calculated for the whole population and by 5 -year age groups. The probabilities of readmission at one-month and one-year were estimated using Kaplan-Meier curves and the log rank test was used to test for statistically significant differences between age groups; individuals were censored at the time they died.

The LOS for the index admission and re-admissions was summarised as the mean number of days (with standard deviation), and presented for the whole population and by 5 -year age groups. Linear regression was used to examine differences in LOS between age groups, after adjusting for potential confounding variables (age, gender, Charlson Index based on hospital separation codes for the index admission, geography using the ARIA index, and socioeconomic status using SEIFA quintiles). LOS data are not normally distributed (highly skewed to the right) and a robust variance estimator was used to correct for this. Cox proportional hazards modelling were used to assess the impact of potential risk factors for readmission to hospital. Where there was a missing value for any outcome or co-variate, the record was excluded from the analysis; this affected fewer than $3 \%$ of observations in the dataset. We tested the assumption of proportional hazards by examining the graph of the $\log (-\log ($ survival $))$ versus log survival time graph.
Mortality rates and median survival time were calculated from first admission for heart failure or hypertensive heart disease. Survival from index admission to death was estimated using Kaplan-Meier curves, with curves fitted by 5 -year age groups. The log rank test was used to test for statistically significant differences between age groups.

All analyses were done using SAS version V9.1 (SAS Institute Inc., Cary, NC, USA) and analyses performed at the $5 \%$ significance level.

The study was approved by the NSW Population and Health Service and University of Newcastle Research Ethics Committees.

\section{Results}

There were 14,972,359 hospital separations in the APDC between 1 July 2000 and 30 June 2007, 67,018 of which had a principal diagnosis ICD-10 code of I50, I11 or I13, representing 41,904 persons. Of these, 29,735 persons had not been hospitalised with these separation codes (any position) in the two years prior to this event. Removing the 574 people aged $<45$ years at the index admission left 29,161 persons (with 645,245 separations) to form the heart failure study cohort. Patients with hypertensive heart disease comprised $<2 \%$ of the study population.

\section{Demographic characteristics}

Most patients $(67.9 \%)$ were $\geq 75$ years of age and $28.7 \%$ were aged $\geq 85$ years (Table 1 ). There were approximately equal numbers of males and females in the cohort (14,604 males, 14,557 females). Females represented around one-third of those aged 45-64 years, but just under two-thirds $(63.5 \%)$ of those aged $\geq 85$ years (data not shown).

\section{Comorbidity burden}

Patients had a median of 2.0 comorbidities recorded at baseline admission, although the range was wide (0-13, not including heart failure), with some evidence of an increase in comorbidity burden over time (Table 2). Re-calculation of the Charlson Index from hospital separation codes at the index admission and all admissions in the previous two years combined did not change the estimates substantially. Across the cohort this had the effect of increasing the mean number of comorbidities per patient by 0.5 , with the median number of recorded comorbidities increasing from 2.0 to 3.0 .

The most commonly recorded co-morbidities at the index admission were diabetes with chronic complications (27\% of patients), pulmonary disease $(15.6 \%)$, renal disease (14.2\%), dementia (5.9\%), acute myocardial infarction (5.3\%), peripheral vascular disease (4.2\%), and cerebral vascular disease (3.4\%). 
Table 1 Number and percent of index admissions by gender, age group, marital status, diagnosis and ARIA and SEIFA indices

\begin{tabular}{|c|c|c|c|c|c|c|c|c|c|c|}
\hline & \multicolumn{2}{|c|}{$\begin{array}{c}2002-03^{*} \\
\mathrm{~N}^{+}=5854\end{array}$} & \multicolumn{2}{|c|}{$\begin{array}{l}2003-04 \\
\mathrm{~N}=5935 \\
\end{array}$} & \multicolumn{2}{|c|}{$\begin{array}{l}2004-05 \\
N=5606\end{array}$} & \multicolumn{2}{|c|}{$\begin{array}{l}2005-06 \\
\mathrm{~N}=5813 \\
\end{array}$} & \multicolumn{2}{|c|}{$\begin{array}{l}2006-07 \\
N=5953\end{array}$} \\
\hline & $\mathrm{n}$ & $\%$ & $\mathrm{n}$ & $\%$ & $\mathrm{n}$ & $\%$ & $\mathrm{n}$ & $\%$ & $\mathrm{n}$ & $\%$ \\
\hline \multicolumn{11}{|l|}{ Sex } \\
\hline Male & 2899 & 50 & 2924 & 49 & 2804 & 50 & 2983 & 51 & 2994 & 50 \\
\hline Female & 2955 & 50 & 3011 & 51 & 2802 & 50 & 2830 & 49 & 2959 & 50 \\
\hline \multicolumn{11}{|l|}{ Age Group } \\
\hline $45-49$ & 68 & 1.2 & 61 & 1.0 & 54 & 1.0 & 88 & 1.5 & 81 & 1.4 \\
\hline $50-54$ & 114 & 1.9 & 136 & 2.3 & 105 & 1.9 & 127 & 2.2 & 122 & 2.0 \\
\hline $55-59$ & 206 & 3.5 & 201 & 3.4 & 191 & 3.4 & 199 & 3.4 & 212 & 3.6 \\
\hline $60-64$ & 302 & 5.2 & 349 & 5.9 & 302 & 5.4 & 317 & 5.5 & 324 & 5.4 \\
\hline $65-69$ & 472 & 8.1 & 463 & 7.8 & 478 & 8.5 & 423 & 7.3 & 408 & 6.9 \\
\hline $70-74$ & 800 & 14 & 760 & 13 & 683 & 12 & 643 & 11 & 662 & 11 \\
\hline $75-79$ & 1085 & 19 & 1082 & 18 & 1019 & 18 & 1054 & 18 & 1000 & 17 \\
\hline 80-84 & 1256 & 21 & 1205 & 20 & 1209 & 22 & 1205 & 21 & 1316 & 22 \\
\hline $85+$ & 1551 & 26 & 1678 & 28 & 1565 & 28 & 1757 & 30 & 1828 & 31 \\
\hline \multicolumn{11}{|l|}{ Marital Status } \\
\hline Married (including defacto) & 2686 & 46 & 2755 & 46 & 2705 & 48 & 2764 & 48 & 2797 & 47 \\
\hline Never married, widowed, divorced, separated & 2951 & 50 & 2932 & 49 & 2692 & 48 & 2872 & 49 & 3017 & 51 \\
\hline Unknown & 214 & 3.7 & 241 & 4.1 & 180 & 3.2 & 176 & 3.0 & 138 & 2.3 \\
\hline \multicolumn{11}{|l|}{ Diagnosis } \\
\hline Hypertensive heart disease $(111,113)$ & 106 & 1.8 & 84 & 1.4 & 86 & 1.5 & 84 & 1.4 & 83 & 1.4 \\
\hline Congestive heart failure (150.0) & 3918 & 67 & 4018 & 68 & 3848 & 69 & 4151 & 71 & 4365 & 73 \\
\hline Left ventricular failure (I50.1) & 1614 & 28 & 1633 & 27 & 1496 & 27 & 1389 & 24 & 1283 & 22 \\
\hline Heart failure, unspecified (I50.9) & 216 & 3.7 & 200 & 3.4 & 176 & 3.1 & 189 & 3.3 & 222 & 3.7 \\
\hline \multicolumn{11}{|l|}{ ARIA } \\
\hline Highly Accessible & 4264 & 75 & 4393 & 76 & 4164 & 76 & 4315 & 76 & 4394 & 76 \\
\hline Accessible & 1159 & 20 & 1131 & 20 & 1022 & 19 & 1081 & 19 & 1099 & 19 \\
\hline Moderately Accessible & 206 & 3.6 & 194 & 3.4 & 217 & 4.0 & 186 & 3.3 & 178 & 3.1 \\
\hline Remote / Very Remote & 72 & 1.3 & 65 & 1.1 & 52 & 1.0 & 72 & 1.3 & 76 & 1.3 \\
\hline \multicolumn{11}{|l|}{ SEIFA $\$$} \\
\hline Most Disadvantaged (1) & 784 & 14 & 771 & 13 & 666 & 12 & 759 & 13 & 713 & 12 \\
\hline 2 & 985 & 17 & 1005 & 17 & 942 & 17 & 965 & 17 & 1042 & 18 \\
\hline 3 & 1308 & 22 & 1356 & 23 & 1292 & 23 & 1326 & 23 & 1313 & 22 \\
\hline 4 & 1220 & 21 & 1243 & 21 & 1242 & 22 & 1264 & 22 & 1299 & 22 \\
\hline Most Advantaged (5) & 1526 & 26 & 1528 & 26 & 1438 & 26 & 1452 & 25 & 1514 & 2 \\
\hline
\end{tabular}

* Financial Year (1 July - 30 June).

$+\mathrm{N}=$ number of persons with index admissions.

* Data not available for all cohort members.

Age-specific and gender-specific rates of index admissions for heart failure

The rates of an index admission for heart failure increased consistently with increasing age; and were higher for males than females for all age groups (Table 3). Index admission rates decreased over time; the age-standardised rates for males decreased from 256.7 to 237.7 per 100,000 from
2002-3 to 2006-7 and for women from 235.3 to $217.1 /$ 100,000 . These trends over time were statistically significant ( $\mathrm{p}=0.0073$, adjusted for gender).

\section{Hospital readmissions and deaths}

Of the 29,161 patients, 7,415 had a readmission (for any cause) within 28 days; 18,493 had one or more readmissions 
Table 2 Co-morbidity burden assessed by Charlson Index

\begin{tabular}{|c|c|c|c|c|c|c|}
\hline Variable & Statistic & $\begin{array}{l}2002-03^{*} \\
(\mathrm{~N}=5854)\end{array}$ & $\begin{array}{l}2003-04 \\
(\mathrm{~N}=5935) \\
\end{array}$ & $\begin{array}{l}2004-05 \\
(\mathrm{~N}=5606)\end{array}$ & $\begin{array}{l}2005-06 \\
(\mathrm{~N}=5813) \\
\end{array}$ & $\begin{array}{l}2006-07 \\
(N=5953)\end{array}$ \\
\hline Charlson Score & mean $(s d)$ & $2.2(1.5)$ & $2.2(1.5)$ & $2.5(1.6)$ & $2.3(1.5)$ & $2.4(1.6)$ \\
\hline \multirow[t]{2}{*}{ (based on index admission) } & median & 2.0 & 2.0 & 2.0 & 2.0 & 2.0 \\
\hline & $(q 1, q 3)$ & $(1.0,3.0)$ & $(1.0,3.0)$ & $(1.0,3.0)$ & $(1.0,3.0)$ & $(1.0,3.0)$ \\
\hline Charlson Score & mean $(\mathrm{sd})$ & $2.7(1.8)$ & $2.8(1.9)$ & $3.0(2.0)$ & $2.8(1.9)$ & $2.9(2.0)$ \\
\hline \multirow[t]{2}{*}{ (based on two years history) } & median & 2.0 & 2.0 & 3.0 & 3.0 & 3.0 \\
\hline & $(q 1, q 3)$ & $(1.0,4.0)$ & $(1.0,4.0)$ & $(1.0,4.0)$ & $(1.0,4.0)$ & $(1.0,4.0)$ \\
\hline
\end{tabular}

* Financial Year (1 July - 30 June).

$+\mathrm{N}=$ number of persons with index admissions.

$\mathrm{sd}=$ standard deviation; $\mathrm{q} 1, \mathrm{q} 3=$ quartile 1 , quartile 3 .

within one year of the index admission, giving readmission rates of $27 \%$ and $73 \%$ at 28 days and one year respectively (Table 4). Readmissions attributed to heart failure were $11 \%$ and $32 \%$ at 28 days and one year respectively (Figure 1). The proportions of readmissions attributed to an exacerbation of heart failure increased with age (Table 5). Heart failure readmission rates at one year increased by age from approximately $25 \%$ in the $45-49$ year age group to $37 \%$ in people aged $\geq 85$ years (data not shown).
All-cause mortality rates were $10 \%$ at 28 days and $28 \%$ at one year (Table 4). As expected, there were age-related trends, with 28 day and one year mortality increasing from $4.1 \%$ and $13.1 \%$ in those aged $45-49$, up to $14.9 \%$ and $41.8 \%$ in those aged $\geq 85$ years. Median survival after a heart failure index admission ranged from about 1.5 years in those aged over 85 , three years for those aged $80-85$, 4 years for those aged $75-79$ to even longer for those younger than 75 (Figure 2).

Table 3 Age-specific and age-standardised rates of index admission by gender and financial year

\begin{tabular}{|c|c|c|c|c|c|c|}
\hline \multirow[b]{2}{*}{5 Year Age group } & \multirow[b]{2}{*}{ Gender } & \multicolumn{5}{|c|}{ Rate of admission (per 100000 persons aged $\geq 45$ years) } \\
\hline & & $2002-03^{*}$ & $2003-04$ & $2004-05$ & $2005-06$ & $2006-07$ \\
\hline $45-49$ & Male & 19.4 & 16.2 & 14.7 & 27.8 & 20.9 \\
\hline$n=352$ & Female & 9.9 & 9.7 & 7.9 & 8.6 & 12.1 \\
\hline $50-54$ & Male & 33.8 & 37.0 & 30.8 & 40.6 & 39.1 \\
\hline$n=604$ & Female & 19.1 & 25.9 & 17.4 & 17.2 & 15.5 \\
\hline $55-59$ & Male & 70.8 & 65.4 & 64.5 & 63.1 & 67.2 \\
\hline$n=1009$ & Female & 38.2 & 37.3 & 30.7 & 33.8 & 34.6 \\
\hline $60-64$ & Male & 132.8 & 155.7 & 131.5 & 137.3 & 130.8 \\
\hline$n=1594$ & Female & 75.8 & 79.3 & 64.5 & 60.6 & 61.9 \\
\hline $65-69$ & Male & 236.0 & 226.2 & 237.9 & 211.5 & 190.1 \\
\hline$n=2244$ & Female & 152.1 & 147.5 & 139.9 & 116.1 & 119.0 \\
\hline $70-74$ & Male & 413.8 & 432.9 & 391.6 & 357.5 & 345.8 \\
\hline$n=3548$ & Female & 311.9 & 271.6 & 249.7 & 247.1 & 266.8 \\
\hline $75-79$ & Male & 691.5 & 678.1 & 620.0 & 686.9 & 652.6 \\
\hline$n=5240$ & Female & 493.7 & 486.3 & 466.2 & 442.4 & 420.4 \\
\hline $80-84$ & Male & 1165.3 & 1092.9 & 1026.5 & 1058.1 & 1133.1 \\
\hline$n=6191$ & Female & 886.5 & 799.5 & 792.6 & 729.2 & 774.5 \\
\hline $85+$ & Male & 1950.3 & 1864.6 & 1781.1 & 1871.3 & 1784.9 \\
\hline$n=8379$ & Female & 1430.5 & 1602.6 & 1393.9 & 1493.9 & 1496.0 \\
\hline \multirow[t]{2}{*}{ Age Standardised } & Male & 256.7 & 252.6 & 236.1 & 244.1 & 237.7 \\
\hline & & $(247.4,266.1)$ & $(243.4,261.7)$ & $(227.4,244.8)$ & $(235.4,252.8)$ & $(229.2,246.2)$ \\
\hline Rate & Female & 235.3 & 236.8 & 215.7 & 213.2 & 217.1 \\
\hline$(95 \%$ Cl) & & $(226.8,243.8)$ & $(228.3,245.2)$ & $(207.8,223.7)$ & $(205.4,221.1)$ & $(209.3,224.9)$ \\
\hline
\end{tabular}

* Financial Year (1 July - 30 June). 
Table 4 Patients with specified events and risk for events within 28 days and 1 year of the index admission

\begin{tabular}{lccccc}
\hline Outcome & \multicolumn{2}{c}{ At 28 days } & & \multicolumn{2}{c}{ Within 1 year } \\
\cline { 2 - 3 } & $\begin{array}{c}\text { Number } \\
\text { of Persons }\end{array}$ & $\begin{array}{c}\text { Probability } \\
\text { of Outcome }\end{array}$ & & $\begin{array}{c}\text { Number } \\
\text { of Persons }\end{array}$ & $\begin{array}{c}\text { Probability } \\
\text { of outcome }\end{array}$ \\
\hline $\begin{array}{l}\text { Re-admission } \\
\text { for any cause }\end{array}$ & 7415 & 0.27 & & 18493 & 0.73 \\
$\begin{array}{l}\text { Readmission - } \\
\text { heart failure* }\end{array}$ & 3007 & 0.11 & & 7848 & 0.32 \\
$\begin{array}{l}\text { All-cause } \\
\text { mortality }\end{array}$ & 2531 & 0.10 & & 6890 & 0.28 \\
$\begin{array}{l}\text { Readmission } \\
\text { or death }\end{array}$ & 9471 & 0.35 & & 21125 & 0.79 \\
$\begin{array}{l}\text { Readmission } \\
\text { HF or death }\end{array}$ & 5302 & 0.20 & & & \\
\hline
\end{tabular}

* heart failure or hypertensive heart disease as principal separation code.

t derived from Kaplan-Meier curves.

\section{Length of stay}

There were strong and statistically significant agerelated trends for LOS for the index admission, readmissions for any cause and heart failure readmissions (Table 6). Readmissions for heart failure were longer than readmissions for any cause for the entire cohort ( 8.3 versus 4.8 days) and for all age groups. In the case of those aged $\geq 85$ years, the mean duration of a heart failure readmission was comparable to that of the index admission ( 9 versus 9.6 days).

\section{Burden on hospital health services}

There were a total of 954,888 hospital bed-days for any cause over the 5 years of this study (Table 7). Of these, 383,646 hospital bed-days were specifically for heart failure, with 321,281 (83.7\%) of these occurring in the first year post index admission. Of those in the first year, 106,679 (33.2\%) of the bed-days related to subjects aged $\geq 85$ years

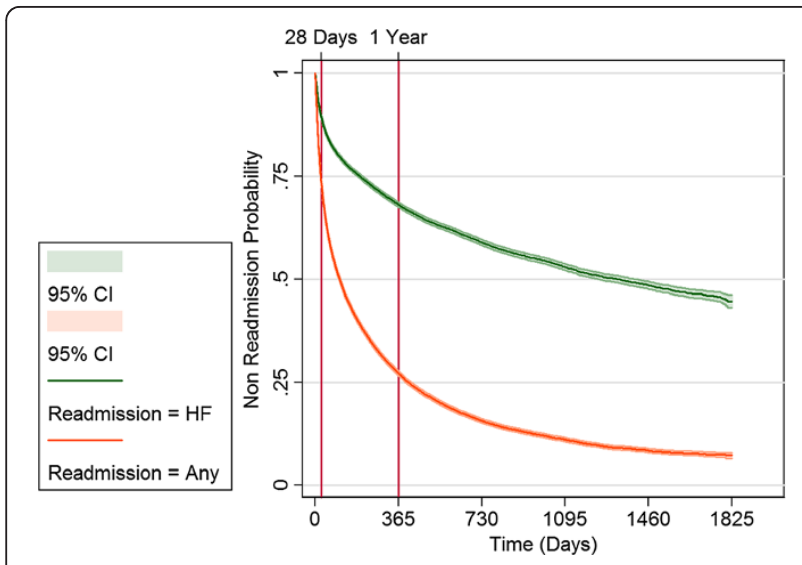

Figure 1 Kaplan-Meier curves for time to heart failure readmission and time to any readmission.

\section{Risk factors for hospital readmission}

A Cox regression model indicated that the major risk factors for any readmission were increasing age, increasing Charlson score, and male gender (Table 8).

\section{Discussion}

This study used linked administrative data to provide a picture of the typical trajectory of a heart failure patient from the time of initial admission, and to demonstrate the health system impacts of heart failure in New South Wales. The most important observations were the high rates of hospital admission to hospital, the age dependence of incidence rates and the $7-8 \%$ reduction in the rates of index admissions noted over the study period. There is substantial morbidity after a diagnosis of heart failure, with consequent health system impacts due to high readmission rates for heart failure, and long durations of hospital stay, particularly in the older age groups. Mortality was high at one year, although many deaths were not attributed to heart failure.

Consistent with other studies [2,5,13], we demonstrated a more than 10 fold increase in index admission rates for those aged $\geq 65$ years compared to those aged $45-64$ years. Incidence rates were higher for males than females at all ages, though the longer female life expectancy meant there were more females than males in the cohort in the oldest age groups ( $\geq 80$ years). Age-standardised rates decreased over time in both males and females, a finding consistent with other studies and settings [7,14-16].

Direct comparisons of our estimates with other studies are challenging because of differences in the data sources used and the standardisation applied. Based on 4812 index admissions for heart failure between 2002 and 2005 in Western Australia, Teng et al [7] concluded agestandardised admission rates for heart failure of 249/ 100,000 and 176/100,000 for men and women respectively, with $41 \%$ of admissions in those aged $<75$ years. We found only $34 \%$ of index heart failure admissions were in those aged $<75$ years, and our age standardised rates were higher at 257 and 235 per 100,000 for males and females respectively in 2002-3, the first year of our analysis. Our standardisation was only for those aged $\geq 45$ years as heart failure before the age of 45 is likely to be due to different aetiology, e.g. congenital heart disease; Teng et al used the population aged $\geq 20$ years for the denominator and a look back period of 10 years to ensure first admission for heart failure, the limitations of our dataset meant we could only apply a two year look back period.

Najafi and colleagues [5] used Australian national data for 2003-4 on all episodes of care for heart failure (both index admissions and readmissions) and age adjustment based on a 'European' population standard to derive agestandardised separation rates for heart failure as principal 
Table 5 Proportion of readmissions attributed to heart failure within $\mathbf{2 8}$ days and one year of the index admission

\begin{tabular}{|c|c|c|c|c|c|c|}
\hline \multirow[t]{2}{*}{ Age Group } & \multicolumn{3}{|c|}{ Readmissions within 28 days } & \multicolumn{3}{|c|}{ Readmissions within 1 year } \\
\hline & Any cause & Heart Failure* & $\%$ of readmissions & Any cause & Heart Failure* & $\%$ of readmissions \\
\hline Whole population & 7415 & 3007 & 41 & 18493 & 7848 & 40 \\
\hline $45-49$ & 107 & 36 & 34 & 221 & 80 & 36 \\
\hline $50-54$ & 155 & 48 & 31 & 366 & 124 & 34 \\
\hline $55-59$ & 288 & 76 & 36 & 663 & 219 & 33 \\
\hline $60-64$ & 423 & 131 & 31 & 1012 & 378 & 37 \\
\hline $65-69$ & 598 & 210 & 35 & 1447 & 575 & 40 \\
\hline $70-74$ & 905 & 321 & 36 & 2274 & 911 & 40 \\
\hline $75-79$ & 1297 & 496 & 38 & 3453 & 1425 & 41 \\
\hline $80-84$ & 1565 & 656 & 42 & 3985 & 1717 & 43 \\
\hline $85+$ & 2077 & 1033 & 50 & 5072 & 2419 & 48 \\
\hline
\end{tabular}

* heart failure or hypertensive heart disease as principal separation code.

diagnosis of 210 per 100,000 for males and 150 per 100,000 person-years for females. Using similar US hospital discharge data standardised to the 2000 US population, Fang et al [2] reported age-adjusted hospitalisation rates of 390 per 100,000, more than double the Australian estimate. These discrepancies likely reflect the methodological differences in coding procedures, admission policies, and differences in treatment thresholds and practices.

\section{Co-morbidities}

The median number of co-morbidities recorded for our cohort was low, regardless of whether the Charlson Index was based on records for the index admission only, or including admissions in the previous two years [17]. Despite likely under-reporting of co-morbidities in the APDC [18], our data showed similar co-morbidity profiles to those reported elsewhere $[2,19]$. The three most commonly recorded co-morbidities in our data set

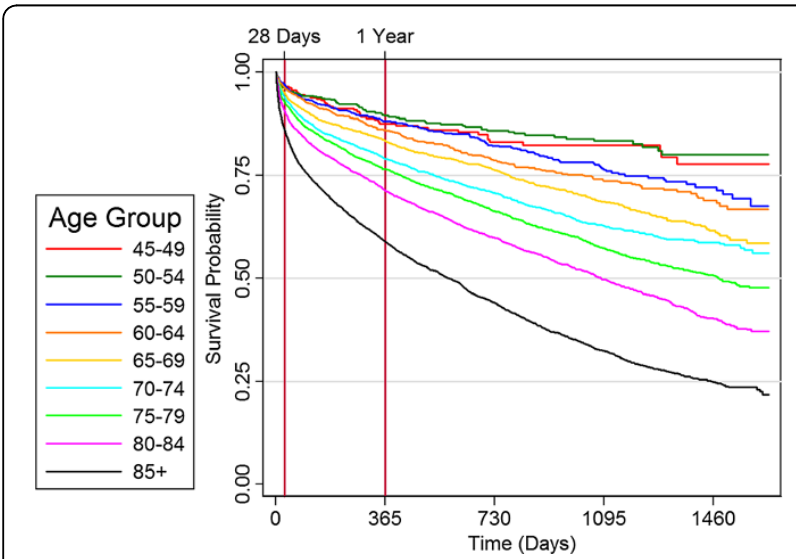

Figure 2 Kaplan-Meier curves for time to death for each 5 year age group for patients over 45 year of age. were diabetes (27\%), pulmonary disease $(15.4 \%)$ and renal failure (14.2\%). These co-morbidities are predictors of higher patient treatment costs, particularly in the last six months of life [20,21]. In our study, increasing age, increasing Charlson comorbidity score and male gender were risk factors for hospital readmission.

\section{Hospital readmission and deaths}

Overall readmission rates were high. We found readmission rates of $27 \%$ at 28 days for any cause $(73 \%$ at one year) and $11 \%$ for admissions due to heart failure $(32 \%$ at one year) with strong age-related trends. Our estimate of $32 \%$ heart failure readmissions at one year is likely to be an underestimate as we only counted readmissions where heart failure was the principal separation code.

Overall mortality rates were $10 \%$ at 28 days and $28 \%$ at one year, similar to those reported by Teng et al (30-day and one year mortality rates $9.5 \%$ and $26.7 \%$ respectively) in Western Australia [7] and by Bueno et al in a US Medicare population (30-day mortality rate $10.7 \%$ in 2006) [22]. Mortality rates increased consistently with age, and the poor heart failure prognosis was most marked in the older age groups.

\section{Length of stay (LOS)}

The mean LOS for the index admission for the entire cohort was 7.8 days, and increased with increasing age, both for the index admission and for readmissions (all cause and for heart failure). Our estimates are higher than some US estimates (mean LOS 4-5 days [1], and 6.4 days in a Medicare population [22]), although comparable to LOS reported in the UK (median LOS 7 days for those aged $<75$ years and 8 days for those aged $\geq 75$ years [23]). The mean duration of readmissions for heart failure was longer than for any cause and, for most age-groups comparable to the duration of the index admission. This highlights the need to 
Table 6 Mean length of stay in days for index admission and readmissions

\begin{tabular}{lcccc}
\hline Age group & $\begin{array}{l}\text { Number of } \\
\text { patients }\end{array}$ & \multicolumn{4}{l}{ Mean LOS in days } \\
\cline { 3 - 5 } & & $\begin{array}{l}\text { Index } \\
\text { admission } \\
\text { Mean (SD) }\end{array}$ & $\begin{array}{l}\text { Readmission } \\
\text { for any cause } \\
\text { Mean (SD) }\end{array}$ & $\begin{array}{l}\text { Heart failure } \\
\text { readmission* } \\
\text { Mean (SD) }\end{array}$ \\
\hline $\begin{array}{l}\text { Whole } \\
\text { population }\end{array}$ & 29161 & $7.8(18.1)$ & $4.8(12.1)$ & $8.3(12.1)$ \\
$45-49$ & 352 & $5.9(6.5)$ & $2.1(6.0)$ & $5.7(7.6)$ \\
years & & & & \\
$50-54$ & 604 & $6.3(7.9)$ & $2.7(5.5)$ & $7.0(7.2)$ \\
$55-59$ & 1009 & $5.9(6.7)$ & $2.4(6.1)$ & $8.0(12.1)$ \\
$60-64$ & 1594 & $6.2(6.0)$ & $3.3(7.5)$ & $7.4(8.3)$ \\
$65-69$ & 2244 & $6.6(7.2)$ & $3.6(8.1)$ & $7.9(9.4)$ \\
$70-74$ & 3548 & $6.9(7.8)$ & $3.9(9.0)$ & $8.1(9.8)$ \\
$75-79$ & 5240 & $7.2(7.3)$ & $4.7(11.5)$ & $8.2(12.3)$ \\
$80-84$ & 6191 & $7.6(9.5)$ & $6.0(12.8)$ & $8.4(9.5)$ \\
$85+$ & 8379 & $9.6(31.2)$ & $8.5(20.4)$ & $9.0(15.8)$ \\
\hline
\end{tabular}

${ }^{*}$ heart failure or hypertensive heart disease as principal separation code. stabilise patients with heart failure before discharge, particularly the oldest patients.

\section{Bed-day usage}

Use of acute hospital resources was substantial, with the patients occupying almost 200,000 bed-days per year in NSW over the five year study period. Of these, around 77,000 bed-days per year were attributed to admissions (index or readmissions) where heart failure was the principal separation diagnosis. Had we included readmissions where heart failure was an additional diagnosis and contributory factor, our estimates would have been even higher. Most notable is the impact of the disease on the elderly. The bed-days analysis included 8,370 patients aged $\geq 85$ years. In the first year (index and readmissions), these patients accounted for 106,679 acute hospital bed-days and around $60 \%$ of these were for elderly women $(66,920 / 106,679)$, reflecting the higher proportion of women in the older age groups and the longer LOS for these patients.

\section{Typical patient and typical trajectory}

This unique dataset allows us to formulate a "typical" heart failure patient and "typical" trajectory from first hospital

Table 7 Hospital bed-days occupied during study period (2002-2007)

\begin{tabular}{|c|c|c|c|c|}
\hline \multirow[b]{2}{*}{ Age group } & \multirow[b]{2}{*}{ Gender } & \multirow[b]{2}{*}{ 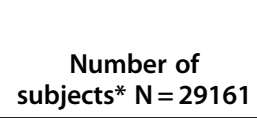 } & \multicolumn{2}{|c|}{ Number of hospital bed-days } \\
\hline & & & $\begin{array}{l}\text { Index admissions + } \\
\text { readmissions any cause }\end{array}$ & $\begin{array}{c}\text { Index admissions + } \\
\text { readmissions for heart failure }\end{array}$ \\
\hline \multirow[t]{2}{*}{$45-49$} & Male & 236 & 7799 & 2121 \\
\hline & Female & 116 & 3803 & 1117 \\
\hline \multirow[t]{2}{*}{$50-54$} & Male & 396 & 9484 & 3739 \\
\hline & Female & 208 & 5587 & 2133 \\
\hline \multirow[t]{2}{*}{$55-59$} & Male & 664 & 24613 & 7489 \\
\hline & Female & 345 & 12247 & 3852 \\
\hline \multirow[t]{2}{*}{$60-64$} & Male & 1068 & 36294 & 12262 \\
\hline & Female & 526 & 17004 & 5737 \\
\hline \multirow[t]{2}{*}{$65-69$} & Male & 1374 & 48279 & 17634 \\
\hline & Female & 870 & 30220 & 10182 \\
\hline \multirow[t]{2}{*}{$70-74$} & Male & 2015 & 65630 & 24480 \\
\hline & Female & 1533 & 55206 & 19534 \\
\hline \multirow[t]{2}{*}{$75-79$} & Male & 2830 & 96495 & 36486 \\
\hline & Female & 2410 & 84129 & 31738 \\
\hline \multirow[t]{2}{*}{$80-84$} & Male & 2971 & 98375 & 39050 \\
\hline & Female & 3220 & 108054 & 44089 \\
\hline \multirow[t]{2}{*}{$85+$} & Male & 3050 & 95002 & 46032 \\
\hline & Female & 5329 & 156667 & 75971 \\
\hline \multirow[t]{2}{*}{ Total } & Male & 14604 & 481971 & 189293 \\
\hline & Female & 14557 & 472917 & 194353 \\
\hline
\end{tabular}


Table 8 Cox regression models with time to any readmission as the outcome

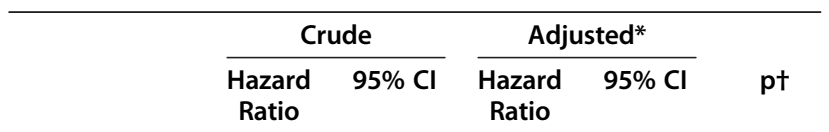

\begin{tabular}{|c|c|c|c|c|c|}
\hline \multicolumn{6}{|l|}{ Sex } \\
\hline Male & 1 & & 1 & & \\
\hline Female & 0.95 & $0.92,0.98$ & 0.93 & $0.89,0.96$ & $<.0001$ \\
\hline \multicolumn{6}{|l|}{ Age Group } \\
\hline$<55$ & 1 & & 1 & & \\
\hline $55-59$ & 1.10 & $0.99,1.22$ & 1.03 & $0.90,1.18$ & 0.6189 \\
\hline $60-64$ & 1.07 & $0.98,1.18$ & 1.00 & $0.89,1.13$ & 0.9971 \\
\hline $65-69$ & 1.12 & $1.03,1.23$ & 1.03 & $0.92,1.16$ & 0.5847 \\
\hline $70-74$ & 1.12 & $1.03,1.22$ & 1.05 & $0.94,1.17$ & 0.3873 \\
\hline $75-79$ & 1.21 & $1.12,1.31$ & 1.12 & $1.00,1.24$ & 0.0437 \\
\hline $80-84$ & 1.22 & $1.12,1.32$ & 1.15 & $1.03,1.28$ & 0.0101 \\
\hline $85+$ & 1.23 & $1.13,1.33$ & 1.14 & $1.02,1.27$ & 0.0167 \\
\hline Charlson Index & 1.06 & $1.06,1.07$ & 1.07 & $1.06,1.09$ & $<0.0001$ \\
\hline $\begin{array}{l}\text { Index Length } \\
\text { of stay }\end{array}$ & 1.00 & $1.00,1.00$ & 1 & $1.00,1.00$ & 0.0006 \\
\hline \multicolumn{6}{|l|}{ Hypertension } \\
\hline No & 1 & & 1 & & \\
\hline Yes & 1 & $0.97,1.02$ & 0.98 & $0.95,1.02$ & 0.4133 \\
\hline \multicolumn{6}{|l|}{ Depression } \\
\hline No & 1 & & & & \\
\hline Yes & 1.01 & $0.91,1.12$ & 0.99 & $0.85,1.14$ & 0.8582 \\
\hline
\end{tabular}

* models were adjusted for age, sex, marital status, ARIA category, SEIFA quintile, financial class, hospital type, Charlson Index, length of stay, hypertension, depression.

† P-values and confidence intervals calculated in SAS.

admission; these also suggest policy directions for health decision makers.

The typical patient is aged over 75 years, more likely to be female at this age, and with two co-morbidities, although the incidence has been decreasing over the last 5 years. Given that the burden of disease is in the elderly, prevention is the key to controlling this condition. The reduction in CHF may be partly due to the fall in AMI [14], better control of hypertension [24], and adherence to evidence-based guidelines for the management of chronic heart failure [25].

There is a high all cause re-admission rate, with $27 \%$ of patients being readmitted within the first 28 days, and $73 \%$ readmitted in the first year; on average $40 \%$ of these readmissions are due to $\mathrm{CHF}$, and those readmissions are longer (8.3 days) than the initial admission (7.8 days). These figures suggest that chronic disease management plans are important to educate patients about controlling CHF. Community based outreach programs may be nurse-led interventions or involve multidisciplinary teams, with evidence that these heart failure specific management programs can reduce mortality and improve quality of life [26]. However, these multifaceted interventions may not always reduce readmission rates [27], and a large US trial of telemonitoring of heart failure patients failed to show differences in readmissions for any reason or death from any cause with this enhanced patient surveillance [28].

Patients with CHF use 200,000 bed-days per year in a state with a population of around 6 million people; over $80 \%$ of these bed days in the first year after the index admission. Failure to adequately stabilise patients before hospital discharge risks early re-admission and, particularly in the elderly, the duration of re-admissions can be long. With hospitals under cost and bed-occupancy pressures, these impacts can be substantial. Intensive specialist clinics and outpatient programs within the first few weeks of first hospital admission may be able to reduce this burden on the hospital system.

Median survival from time of initial diagnosis for CHF is 1.5 years for those aged $>85$ and about 3 years for those aged 80-85. This prognosis is similar to many cancers [29], and highlights the need to address palliative care issues in the management of CHF. Recent studies indicate that medical admissions tend to be concentrated in the last 6 months of life, at least in US settings $[20,21]$, and better palliative care programs and more hospice places may avert these acute admissions.

\section{Limitations and strengths of the study}

This study shares the limitations of other data linkage studies, with reliability of study conclusions dependent on the accuracy of the record linkage, the study definitions used and the validity of the coding in the hospital records. A technical assessment of the record linkage quality for this project determined a false positive rate (invalid links) of $0.3 \%$ and a false negative rate (missed links) of $<0.1 \%$. The administrative data sets used in this study contained no information on the medical management of heart failure, in particular use of drugs such as ACE inhibitors, angiotensin receptor blockers and betablockers that have been shown to improve long-term survival.

Examining heart failure presents a particular challenge as it is not a clearly defined disease entity but rather a complex clinical syndrome often following a history of cardiovascular disease or as a complication of diabetes, resulting in ambiguity in its diagnosis and reporting in medical records and hospital separation data. We chose to present readmissions for any cause and those due to heart failure because of the greater reliability of the coding for disease in the primary diagnosis position [30]. We did not refer to the original medical records to confirm a diagnosis of heart failure in the study subjects. However a recent validation study conducted in Western 
Australia using similar datasets concluded a positive predictive value of $99.5 \%$ with a coding of heart failure in the principal diagnostic position [6].

The major strength of this study is that patient-level analyses allowed us to calculate readmission rates, median survival and importantly, quantify the strong agerelated trends in incidence of disease, LOS and mortality. Record linkage studies based on the data sets of the $\mathrm{CHeReL}$ have no selection biases; analyses are based on records of hospital separations for all residents of NSW in both public and private hospitals.

\section{Conclusions}

We found that rates of index admissions for heart failure decreased significantly in both males and females over the study period. Rates of hospital readmission were high and were related to age and the presence of co-morbidities. LOS was longest in the oldest patients and duration of stay similar for both index admissions and readmissions for heart failure. Use of acute hospital resources was substantial, with heart failure patients occupying almost 200,000 bed-days per year in NSW over the five year study period. The strong age-related trends observed have implications for policy planners and decision makers and highlight the importance of stabilising elderly patients before discharge and community-based outreach programs to better manage heart failure and reduce readmissions.

\section{Abbreviations \\ APDC: Admitted Patient Data Collection; ARIA: Accessibility/Remoteness Index of Australia; CHeReL: Centre for Health Record Linkage; ICD: International Classification of Diseases; LOS: Length of stay; NHMD: National Hospital Morbidity Data; NSW: New South Wales; RBDM: Registry of Births Deaths and Marriages; SEIFA: Socio-Economic Indexes for Areas.}

\section{Competing interest}

The authors declare that they have no competing interests.

\section{Acknowledgments}

We thank Daniel Barker for his work in conducting the statistical analyses for the study. We thank the data custodians of the APDC and RBDM for providing the data needed for this study and the CHeReL for providing the data linkage services.

\section{Author details \\ ${ }^{1}$ School of Medicine and Public Health, The University of Newcastle, Newcastle, Australia. ${ }^{2}$ Hunter Medical Research Institute, The University of Newcastle, Newcastle, Australia. ${ }^{3}$ UNSW Cancer Research Centre, University of New South Wales and Prince of Wales Clinical School, Sydney, Australia. ${ }^{4}$ Institute for Clinical Evaluative Sciences and Department of Medicine, University of Toronto, Toronto, Canada. ${ }^{5}$ Clinical Pharmacology, Calvary Mater Hospital, The University of Newcastle, Clinical Sciences Building, Waratah, NSW 2298, Australia.}

\section{Author contributions}

JR, S-AP, JA conceived the study; all authors participated in the study design and interpretation of results; PMcE was responsible for the statistical analyses; JR, DH, JA drafted the manuscript; S-AP, PMCE, KI provided critical review of the manuscript. All the authors read and approved the final manuscript.

\section{Funding}

This research received no specific grant from any funding agency in the public, commercial, or not-for-profit sectors.

Received: 13 June 2011 Accepted: 25 April 2012

Published: 25 April 2012

\section{References}

1. Butler J, Kalogeropoulos A (2008) Worsening heart failure hospitalization epidemic. We do not know how to prevent and we do not know how to treat! (Editorial). J Am Coll Cardiol 52:435-437

2. Fang J, Mensah GA, Croft JB, Keenan NL (2008) Heart failure-related hospitalization in the U.S., 1979 to 2004. J Am Coll Cardiol 52:428-434

3. Clark RA, McLennan S, Dawson A, Wilkinson D, Stewart S (2004) Uncovering hidden epidemic: a study of the current burden of heart failure in Australia. Heart Lung Circ 13:266-273

4. Stewart S, Maclntyre K, Capewell S, McMurray JJV (2003) Heart failure and the aging population: an increasing burden in the 21 st century. Heart 89:49-53

5. Najafi F, Dobson AJ, Jamrozik K (2007) Recent changes in heart failure hospitalisations in Australia. Eur J Heart Fail 9:228-233

6. Teng T-HK, Finn J, Hung J, Geelhoed E, Hobbs M (2008) A validation study: how effective is the Hospital morbidity data as a surveillance tool for heart failure in Western Australia? Aust NZ J Public Health 32:405-407

7. Teng T-HK, Finn J, Hobbs M, Hung J (2010) Heart failure: incidence, case fatality, and hospitalization rates in Western Australia between 1990 and 2005. Circ Heart Fail 3:236-243

8. AlHW, Field B: Heart failure. .... what of the future? Bulletin no.6. AlHW Cat.No. AUS34 2003.

9. Sandararajan V, Henderson T, Perry C, Muggivan A, Quan H, Ghali W (2004) New ICD-10 version of the Charlson Comorbidity Index predicted inhospital mortality. J Clin Epidemiol 57:1288-1294

10. Commonwealth of Australia. Measuring remoteness: accessibility/ remoteness index of Australia (ARIA). Online 2003. [http://www.gisca. adelaide.edu.au]

11. Australian Bureau of Statistics. SEIFA Socio-Economic Indexes For Areas. 2006. [http://www.abs.gov.au/websitedbs/D3310114.nsf/home/ Seifa_entry_page] 4 November 2009.

12. Goldberg A, Borthwick A. The ChoiceMaker2 Record Matching System. November 2004. ChoiceMaker Technologies, Inc. New York, NY 10010. [http:// ww1.prweb.com/prfiles/2005/12/13/322270/ChoiceMakerWhitePaper.pdf] 17 April 2012

13. Neumann T, Biermann J, Neumann A, Wasem J, Ertl G, Dietz R, Erbel R (2009) Heart failure: the commonest reason for hospital admission in Germany. Dtsch Arztebl Int 106(16):269-275

14. Tu JV, Nardi L, Fang J, Liu J, Khalid L, Johansen H, for the Canadian Cardiovascular Outcomes Research Team (2009) National trends in rates of death and hospital admissions related to acute myocardial infarction, heart failure and stroke, 1994-2004. CMAJ 180(13). doi:10.1503/ cmaj.081197

15. Curtis LH, Whellan DJ, Hammill BG, Hernandez AF, Anstrom KJ Shea AM, Schulman KA (2008) Incidence and prevalence of heart failure in elderly persons, 1994-2003. Arch Intern Med 168(4):418-424

16. Jhund PS, Macintyre K, Simpson CR, Lewsey JD, Stewart S, Redpath A, Chalmers JWT, Capewell S, MCMurray JJV (2009) ong-term trends in first hospitalization for heart failure and subsequent survival between 1986 and 2003: a population study of 5.1 million people. Circulation 119 (4):515-523

17. Lee DS, Donovan L, Austin PC, Gong Y, Liu PP, Rouleau JL, Tu JV (2005) Comparison of coding of heart failure and comorbidities in administrative and clinical data for use in outcomes research. Med Care 43:182-188

18. Lee Powell H, Lim LL-Y, Heller RF (2001) Accuracy of administrative data to assess comorbidity in patients with heart disease: an Australian perspective. J Clin Epidemiol 54:687-693

19. Braunstein JB, Anderson GF, Gerstenblith G, Weller W, Niefield M, Herbert R Wu AW (2003) Noncardiac comorbidity increases preventable hospitalizations and mortality among Medicare beneficiaries with chronic heart failure. J Am Coll Cardiol 42:1226-1233

20. Unroe KT, Greiner MA, Hernandez AF, Whellan DJ, Kaul P, Schulman KA, Peterson ED, Curtis LH (2011) Resource use in the last 6 months of life 
among Medicare beneficiaries with heart failure, 2000-2007. Arch Intern Med 171:196-203

21. Kaul P, McAlister FA, Ezekowitz JA, Bakal JA, Curtis LH, Quan H, Knudtson ML, Armstrong PW (2011) Resource use in the last 6 months of life among patients with heart failure in Canada. Arch Intern Med 171(3):211-217

22. Bueno H, Ross JS, Wang Y, Chen J, Vidán MT, Normand S-LT, Curtis JP, Drye EE, Lichtman JH, Keenan PS, Kosiborod M, Krumholz HM (2010) Trends in length of stay and short-term outcomes among Medicare patients hospitalised for heart failure, 1993-2006. JAMA 303(21):2141-2147

23. Nicol ED, Fittall B, Roughton M, Cleland JGF, Dargie H, Cowie MR (2008) NHS heart failure survey: a survey of acute heart failure admissions in England, Wales and Northern Ireland. Heart 94:172-177

24. Sciarretta S, Palano F, Tocci G, Baldini R, Volpe M: Antihypertensive treatment and development of heart failure in hypertension. A bayesian network meta-analysis of studies in patients with hypertension and high cardiovascular risk. Arch Intern Med 2010. doi:10.1001/ archinternmed.2010.427. Published online November 8, 2010.

25. National Heart Foundation of Australia and the Cardiac Society of Australia and New Zealand (Chronic Heart Failure Guidelines Expert Writing Panel). Guidelines for the prevention, detection and management of chronic heart failure in Australia, 2006. [http://www.heartfoundation.org.au/ SiteCollectionDocuments/CHF\%202006\%20Guidelines\%20NHFA-CSANZ\% 20WEB.pdf] 18 February 2011.

26. Velez M, Westerfeldt B, Rahko PS (2008) Why it pays for hospitals to initiate a heart failure disease management program. Disease Management and Health Outcomes 16:155-173

27. Mudge A, Denaro C, Scott I, Bennett C, Hickey A, Jones MA (2010) The paradox of readmission: effect of a quality improvement program in hospitalized patients with heart failure. J Hosp Med 5:148-153. doi:10.1002/jhm.563

28. Chaudhry SI, Mattera JA, Curtis JP, Spertus JA, Herrin J, Lin Z, Phillips CO, Hodshon BV, Cooper LS, Krumholz HM (2010) Telemonitoring in patients with heart failure. N Engl J Med 363:2301-2309

29. Stewart S (2003) Prognosis of patients with heart failure compared with common types of cancer. Heart Fail Monit 3:87-94

30. Grijalva CG, Chung CP, Stein M, Gideon PS, Dyer SM, Mitchel EF, Griffin MR (2008) Computerized definitions showed high positive predictive values for identifying hospitalizations for congestive heart failure and selected infections in Medicaid enrollees with rheumatoid arthritis Pharmacoepidemiol Drug Saf 17:890-895

doi:10.1186/1472-6963-12-103

Cite this article as: Robertson et al.: The health services burden of heart failure: an analysis using linked population health data-sets. BMC Health Services Research 2012 12:103.

\section{Submit your next manuscript to BioMed Central and take full advantage of:}

- Convenient online submission

- Thorough peer review

- No space constraints or color figure charges

- Immediate publication on acceptance

- Inclusion in PubMed, CAS, Scopus and Google Scholar

- Research which is freely available for redistribution 